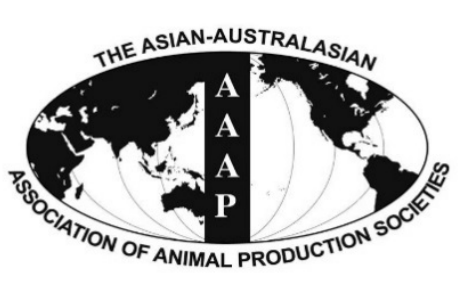

Open Access

Asian Australas. J. Anim. Sci.

Vol. 28, No. 11 : 1599-1605 November 2015

http://dx.doi.org/10.5713/ajas.15.0124

www.ajas.info

pISSN 1011-2367 elSSN 1976-5517

\title{
Effects of Supplemental Mannanoligosaccharides on Growth Performance, Faecal Characteristics and Health in Dairy Calves
}

\author{
Cagdas Kara*, Huseyin Cihan, Mutlu Temizel, Serkan Catik, Yavuz Meral, \\ Abdulkadir Orman, Artun Yibar, and Hidir Gencoglu \\ Faculty of Veterinary Medicine, University of Uludag, Bursa, Gorukle 16059, Turkey
}

\begin{abstract}
Twenty Holstein calves were used to investigate the effects of mannanoligosaccharides (MOS) supplementation in the whole milk on growth performance, faecal score, faecal $\mathrm{pH}$, selected faecal bacterial populations and health during the preweaning period. Healthy calves selected by clinical examination were allocated to one of the two groups (control [CG] and experimental [EG]) at 5 days old. Each group consisted of 5 male and 5 female calves. Each calf in EG was supplemented with 7 g/d of a MOS product (Celmanax) from 5 days to 56 days of age. MOS supplement was mixed with the whole milk once in the morning and administered to the calves in EG via nipple bottle, whereas the calves in CG were fed the whole milk without MOS. Calves were weaned at 56 days of age. The final body weight, average daily weight gain (ADG) and average daily feed intake (ADFI) were statistically similar ( $p>0.05$ ) but were higher by $3.70 \%, 6.66 \%$, and $10.97 \%$, respectively, in MOS than in control calves. Feed efficiency (ADG/ADFI) was also similar in two calves group. While faecal scores did not differ on day 5, 7, 14, 21, 28, 42, 49, and 56 between groups, EG had a higher faecal score $(\mathrm{p}=0.05)$ than CG on day 35. Faecal concentration of Lactobacillus was lower $(\mathrm{p}<0.05)$ in EG compared with CG. No differences $(p>0.05)$ in faecal concentrations of Bifidobacterium, Clostridium perfringens, and Escherichia coli were found between groups. Although there were no significant differences $(\mathrm{p}>0.05)$ in the incidence of diarrhoea, treatment days for diarrhoea and the costs associated with diarrhoea treatments between groups, collectively, the observed reductions in treatment days and the cost of diarrhoea treatments accompanying increases in final body weight, ADG and ADFI for EG may indicate potential benefit of MOS in treatment of diarrhoea. (Key Words: Calves, Mannanoligosaccharides, Growth Performance, Faecal Characteristics, Health)
\end{abstract}

\section{INTRODUCTION}

The maintenance of calf health and optimizing calf growth are key objectives especially at early stages of life (Ghosh and Mehla, 2012). Intestinal infections and subsequent diarrhoea account for the majority of health problems affecting calves during the preweaning period and are the primary reason for death and poor growth performance in the first 2 months of age (Davis and Drackley, 1998). In this respect, prebiotics have been used to improve the health and performance of calves during the preweaning period (Heinrichs et al., 2003; Ghosh and Mehla, 2012; Heinrichs et al., 2013).

\footnotetext{
* Corresponding Author: Cagdas Kara. Tel: +90-224-294-1248, Fax: +90-224-294-12-02, E-mail: cagdaskara@uludag.edu.tr Submitted Feb. 10, 2015; Revised Apr. 7, 2015; Accepted May 1, 2015
}

Prebiotics are defined as nondigestible carbohydrates that can be able to beneficially modify the growth and/or activity of the intestinal bacterial populations towards a healthier microflora and improve indices of host health (Gibson and Roberfroid, 1995). Fructooligosaccharides (Grand et al., 2013), galactooligosaccharides (Kanakupt et al., 2011) and mannanoligosaccharides (MOS) (Demirel et al., 2007; Ghosh and Mehla, 2012) have been utilized as prebiotic in animals. Supplementation of MOS has become relatively common throughout the world. This substance is available for inclusion in milk, milk replacer and calf starter (Ghosh and Mehla, 2012). MOS are complex mannose sugars derived from the cell wall of Saccharomyces cerevisiae (Spring et al., 2000). The structure of the mannan component of MOS resembles that of the carbohydrates on the intestinal wall. Pathogenic bacteria containing type-I (mannose specific) fimbriae normally adhere to mannans on 
the mucosal surface of the intestine. The mannan component of MOS provides a competitive binding site for certain intestinal pathogens (Newman, 1994; Spring et al., 2000). Therefore, benefits of MOS are associated with pathogen removal from the intestine without attachment and colonization (Spring et al., 2000; Shane, 2001).

In some studies with calves, supplementation with MOS has been shown to increase average daily weight gain (ADG) and feed efficiency (ADG/ADFI [average daily feed intake]) (Ghosh and Mehla, 2012; Heinrichs et al., 2013), to improve faecal score (Heinrichs et al., 2003; Morrison et al., 2010), and to decrease faecal concentrations of bacterial populations such as total coliform and Escherichia coli (Jacques and Newman, 1994; Ghosh and Mehla, 2012). However, other data indicated that supplementation of MOS did not lead to the improvement in growth performance (Hill et al., 2008; Hill et al., 2009) and faecal score (Terre et al., 2007; Uzmay et al., 2011) and the change in faecal bacterial populations (Terre et al., 2007) in calves. Heinrichs et al. (2003) reported that addition of MOS to milk replacer reduced the incidence and severity of diarrhoea in calves. Conversely, Hill et al. (2008) and Uzmay et al. (2011) observed that feeding milk replacer or whole milk containing MOS did not reduce diarrhoea and days with abnormal faecal scores (diarrhoea) in calves.

Results from feeding MOS are variable and are not yet fully conclusive. Because of these different results, further research efforts should continue to evaluate the efficacy of MOS on performance and health in calves. The objective of the current study was to investigate the effects of MOS supplementation on growth performance, faecal score, faecal $\mathrm{pH}$, selected faecal bacterial populations (Lactobacillus, Bifidobacterium, Clostridium perfringens, and $E$. coli) and health in calves.

\section{MATERIALS AND METHODS}

\section{Study area and animals}

The study was carried out at Uludag University Applied Research Center for Veterinary Faculty Unit in Bursa located within the North West Turkey. This study was conducted under an approved protocol by Animal Care and Use Committee of University of Uludag.

Twenty healthy calves (5 days old) of ten each male and female were selected by clinical examination (body temperature, respiration, and pulsation rates), general appearance and occurrence of diarrhoea. Calves were randomly divided into two equal groups (control [CG] and experimental $[\mathrm{EG}]$ ) of five male and five female.

\section{Management and experimental design}

Calves were fed colostrum within $2 \mathrm{~h}$ of birth and housed in individual pens until the end of the study at 56 days of age. Calves received $4 \mathrm{~L} / \mathrm{d}$ of the whole milk from day 2 to 49 and $2 \mathrm{~L} / \mathrm{d}$ of the whole milk during last 7 days of the study. Milk was offered twice daily. Pelleted calf starter and water were given ad libitum from day 5 (the beginning of the study). Pelleted calf starter was containing $19.58 \%$ of crude protein, $5.7 \%$ of crude fat, $22.46 \%$ of neutral detergent fiber, $9.99 \%$ of acid detergent fiber, $3.55 \%$ of acid detergent lignin, $43.23 \%$ of non-fiber carbohydrate and $9.03 \%$ of ash on a dry matter basis. Calves were weaned at 56 days of age.

Each calf in EG was supplemented with $7 \mathrm{~g} / \mathrm{d}$ of a MOS product from 5 days to 56 days of age. MOS supplement was mixed with the whole milk once in the morning and administered to the calves in EG via nipple bottle at the amount recommended by the manufacturer (Celmanax, ViCOR, Mason City, IA, USA). The prebiotic product obtained from cell wall fragments of $S$. cerevisiae contained $51 \%$ of glucan and $25.5 \%$ of mannan according to the certificate of analysis reported by Vi-COR.

\section{Measurements and sample collection}

Individual pelleted calf starter intake was measured daily by collecting residual feed after every feeding during the study. Calves were weighed before feeding at day 5 and 56. ADG, ADFI, and feed efficiency (ADG/ADFI) were calculated for each calf.

Faecal samples were collected from each calf by retrieval from the rectum on day 5, 7, 14, 21, 28, 35, 42, 49, and 56. Faecal samples were scored in respect to consistency by the same researcher on all collection days according to the following system: $1=$ watery, diarrhoea; 2 = soft, unformed; $3=$ soft, formed; $4=$ hard, formed; and 5 $=$ hard, dry pellets. On day 5 and 56 , each faecal sample was diluted 10 folds with distilled water for $\mathrm{pH}$ measurement. The mixture of faecal sample and distilled water was homogenized and faecal $\mathrm{pH}$ was immediately measured using an electronic $\mathrm{pH}$ meter (PT-10, Sartorius AG, Goettingen, Germany) fitted with a glass electrode. Faecal samples could be collected from 8 of 10 and 9 of 10 calves in $\mathrm{CG}$ and EG, respectively, on day 56 by retrieval from rectum using sterile gloves. Faecal samples were placed in sterile sampling bags and immediately transported to the laboratory for bacterial enumeration. One $\mathrm{g}$ of each faecal sample was homogenized with $9 \mathrm{~mL}$ of saline peptone water in a stomacher laboratory blender (Stomacher 80 Biomaster, Seward Inc., Port Saint Lucie, FL, USA). Subsequently, serial 10-fold dilutions were made in saline peptone water and plated onto relevant selective media. Lactobacillus was grown on Man Rogosa Sharpe agar (MRS agar, Hypet Media, Diatek, Istanbul, Turkey). Each plate was incubated at $37^{\circ} \mathrm{C}$ for $48 \mathrm{~h}$ in an anaerobic 
jar (Oxoid AN0035A, Basingstoke, Hampshire, UK) with gas generating sachet (Oxoid CN0020C, Basingstoke). Non-spore-former rods, gram-positive and catalasenegative isolates were regarded as Lactobacillus. Bifidobacterium was grown on Bifidobacterium Selective Medium agar (BSM agar, Hypet Media, Diatek). The plates were incubated at $37^{\circ} \mathrm{C}$ for 48 to $72 \mathrm{~h}$ in anaerobic jar with gas generating sachet. The selected bacterial colonies were investigated with regard to cell morphology by Gram staining. The colonies with gram-positive rods and characteristic bifurcated " $\mathrm{Y}$ " and "V" shapes were recorded as Bifidobacterium. C. perfringens was grown on 4methylumbelliferyl phosphate-supplemented (MUP, Merck 1.00888, Darmstadt, Germany) Tryptose Sulfite Cycloserine agar (TSC agar, Hypet Media, Diatek) containing egg yolk emulsion and selective supplement. Each plate was incubated at $37^{\circ} \mathrm{C}$ for $24 \mathrm{~h}$ in an anaerobic jar with gas generating sachet. Each presumptive black colony was added to $10 \mathrm{~mL}$ of Thioglycolate Broth (Merck 1.08190) and then incubated at $37^{\circ} \mathrm{C}$ for 16 to $18 \mathrm{~h}$. Activated cultures were prepared for identifying by characteristic colony morphology, Gram staining and biochemical tests. The colonies with gram-positive and nonmotile rods, lactose positive, nitrate reduction positive, gelatine positive and motility negative were considered to be $C$. perfringens. Total coliform was grown on Violet Red Bile (VRB, Oxoid CM0107, Basingstoke) agar. After 24 to $48 \mathrm{~h}$ of incubation at $37^{\circ} \mathrm{C}$, the red colonies with halos were typical for $E$. coli. The colonies typical for $E$. coli were enumerated and inoculated into Lactose Broth (LB, Oxoid CM0137, Basingstoke) with Durham tube. After 24 to $48 \mathrm{~h}$ of incubation at $44^{\circ} \mathrm{C}$, gas and lactic acid production positive tubes were streaked onto Eosin Methylen Blue (EMB, Oxoid CM0069, Basingstoke) agar and confirmed to be $E$. coli by biochemical tests, such as Indol (SIM, Merck 1.05470), Methyl red and Voges-Proskauer (MR-VP, Merck 1.05712,) and Citrate (Oxoid CM0155, Basingstoke). Indol positive, MR positive, VP negative and citrate negative indicated the presence of E. coli type-1. The bacterial counts were expressed as $\log 10 \mathrm{CFU}$ (colony forming unit) per gram of faecal samples.

Body temperatures were taken per rectum using a digital thermometer at the same times and recorded on day 5, 7, 14, $21,28,35,42,49$, and 56 . Health status of calves was monitored daily during the study. Faecal score of one was considered to be diarrhoea. In addition, tail and/or hind limbs stained with faeces were evaluated as a finding of diarrhoea. Calves with diarrhoea were treated by the farm veterinarian according to protocols established by the Department of Internal Medicine, Faculty of Veterinary Medicine. In the case of calves with diarrhoea, medication used (antibiotics, anti-inflammatory, immun stimulant, and electrolyte products) and dosage and the duration of treatments applied for diarrhoea were recorded throughout the study. Costs associated with diarrhoea treatments were calculated based on current costs for each product and daily dosage for each medication for individual calves.

\section{Statistical analysis}

All statistical analyses were conducted by using SPSS ver. 5.0 (SPSS Inc., Chicago, IL, USA) (SPSS, 2004). Data for body weight, ADFI, ADG, and feed efficiency were tested to determine normal distribution by KolmogorovSmirnov test. Body weight, ADFI, ADG, and feed efficiency were tested for homogeneity of variance and analysed by independent sample T-test. Data for faecal score and faecal $\mathrm{pH}$ were tested to determine normal distribution by Kolmogorov-Smirnov test and F-test, respectively. Faecal score, faecal $\mathrm{pH}$, faecal bacterial populations and body temperature were analysed by independent sample T-test. The incidence of diarrhoea was analysed by chi-square test and Fisher exact test. The statistical analyses for the duration of treatment applied for diarrhoea and the costs associated with diarrhoea treatments were performed by Mann-Whitney test. Differences between groups were considered significant at $p \leq 0.05$.

\section{RESULTS AND DISCUSSION}

Body weight, ADG, ADFI, and feed efficiency measurements are presented in Table 1 . There were no significant differences $(p>0.05)$ in body weight, ADG, ADFI, and feed efficiency between groups during the period from day 5 to 56 after birth. However, body weight at the end of the study, ADG and ADFI values were 3.70\%, $6.66 \%$, and $10.97 \%$ higher for the calves supplemented with MOS than control calves, respectively. Similarly, MOS supplementation led to the numerical increases in final body weight, $\mathrm{ADG}$ and ADFI in other studies with calves

Table 1. Effect of MOS supplementation on growth performance of calves

\begin{tabular}{|c|c|c|c|}
\hline \multirow{2}{*}{ Item } & \multicolumn{2}{|c|}{ Group } & \multirow{2}{*}{ p-value } \\
\hline & $\mathrm{CG}^{\mathrm{a}}(\mathrm{n}=10)$ & $\mathrm{EG}^{\mathrm{b}}(\mathrm{n}=10)$ & \\
\hline Initial body weight (kg) & $36.50 \pm 0.83$ & $37.31 \pm 1.45$ & 0.635 \\
\hline Final body weight (kg) & $59.97 \pm 2.43$ & $62.19 \pm 2.21$ & 0.512 \\
\hline $\operatorname{ADG}(g / d)$ & $450 \pm 40$ & $480 \pm 30$ & 0.604 \\
\hline $\operatorname{ADFI}(\mathrm{g} / \mathrm{d})$ & $597.58 \pm 46.49$ & $663.14 \pm 37.33$ & 0.290 \\
\hline $\begin{array}{l}\text { Feed efficiency }{ }^{c} \\
\text { (g gain/g feed) }\end{array}$ & $0.75 \pm 0.04$ & $0.72 \pm 0.03$ & 0.565 \\
\hline \multicolumn{4}{|c|}{$\begin{array}{l}\text { MOS, mannanoligosaccharides; } \mathrm{CG} \text {, control group; EG, experimental } \\
\text { group; ADG, average daily weight gain; ADFI, average daily starter } \\
\text { concentrate feed intake. } \\
\text { Values are presented as mean } \pm \text { standard error of the mean. } \\
{ }^{\text {a }} \text { Control group. } \\
{ }^{b} \text { Group supplemented with MOS. } \\
{ }^{c} \text { Feed efficiency: ADG/ADFI. }\end{array}$} \\
\hline
\end{tabular}




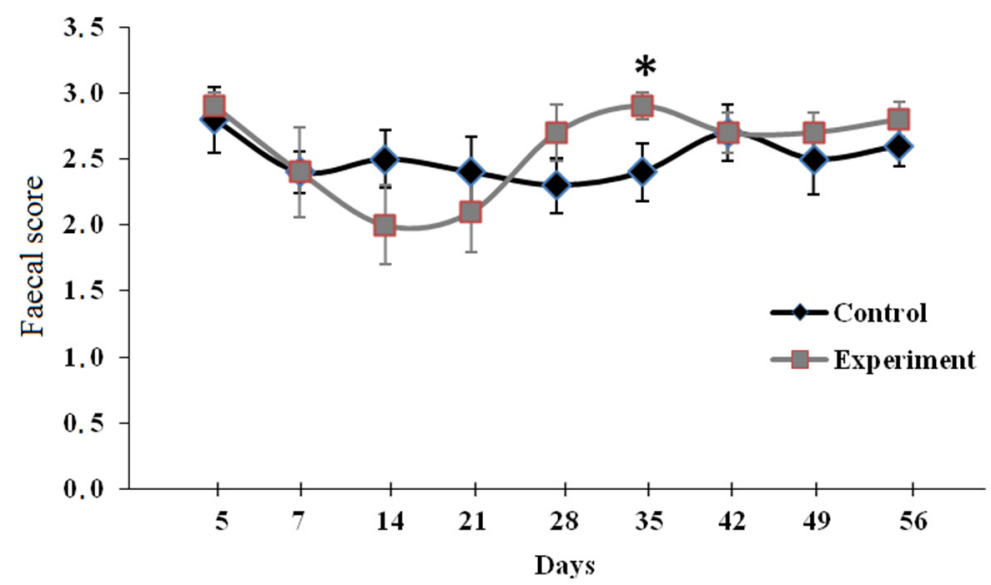

Figure 1. Mean ( \pm standard error of the mean) faecal scores of control $(C G, n=10)$ and experimental $(E G, n=10)$ calves. CG, control group; EG, experimental group. * EG had a higher faecal score $(\mathrm{p}=0.05)$ than $\mathrm{CG}$ on day 35.

(Uzmay et al., 2011; da Silva et al., 2012). Ghosh and Mehla (2012) observed that $4 \mathrm{~g} / \mathrm{d}$ MOS supplementation improved ADG, ADFI, and feed efficiency of calves. White et al. (2002) reported that 3\% MOS addition to diet decreased ADG and ADFI in weanling pigs. These different results of MOS on growth performance of livestock may be caused by level of supplementation of MOS from different sources and manufacturers, the duration of MOS supplementation, as well as nutrient composition of the diet, health status, intestinal bacterial populations and the environmental conditions (Demirel et al., 2007; Zhao et al., 2012).

In the current study, while faecal scores did not differ on day $5,7,14,21,28,42,49$, and 56 between groups, EG had a higher faecal score $(\mathrm{p}=0.05)$ than $\mathrm{CG}$ on day 35 (Figure 1). Based on the results for faecal score in our study, it can be suggested that MOS supplementation had no consistent effect on faecal score. Similarly, da Silva et al. (2012) also observed that $4 \mathrm{~g} / \mathrm{d}$ MOS supplementation improved faecal score of calves only on week one during the experimental period lasting for eight weeks. Grieshop et al. (2004) reported that dietary supplementation with $1 \%$ MOS did not affect faecal score of dogs. Hill et al. (2008) observed no improvement in faecal score when $6 \mathrm{~g} / \mathrm{d}$ of MOS was supplemented to calves. Morrison et al. (2010) reported that calves offered $10 \mathrm{~g} / \mathrm{d}$ of MOS had an improved faecal score. In the study conducted by Ghosh and Mehla (2012), lower faecal score was observed in the calves supplemented with MOS (4 g/d) compared to the control calves. In contrast to our study, a higher faecal score would indicate formation of softer faeces in this study. Ghosh and Mehla (2012) suggested that the improved faecal score might be because of the suppression of pathogenic bacteria responsible for toxin production leading to intestinal secretion and diarrhoea (Giannella, 1983).

In the current study, faecal $\mathrm{pH}$ was not different $(\mathrm{p}>0.05)$ between groups (Table 2). Similarly, Swanson et al. (2002a) reported that supplementation of $2 \mathrm{~g} / \mathrm{d}$ fructooligosaccharides plus $1 \mathrm{~g} / \mathrm{d}$ MOS did not alter ileal and faecal $\mathrm{pH}$ of dogs. In the study conducted by Lebel et al. (2014), no effect of $0.1 \%$ MOS supplementation was observed on intestinal pH of pigs. Ao and Choct (2013) also demonstrated that caecal $\mathrm{pH}$ was not affected by dietary supplementation of MOS in broilers.

MOS is not enzymatically digested in the intestine and pathogenic bacteria bound to MOS are likely removed from the digestive system without attachment and colonization (Spring et al., 2000; Shane, 2001). Some studies in animals have shown that MOS supplementation can increase faecal Lactobacillus and/or Bifidobacteria concentrations (Swanson et al., 2002a; Grieshop et al., 2004) and decrease faecal C. perfringens or E. coli concentrations (Finuance et al., 1999; Grieshop et al., 2004). However, in other studies with MOS, no changes were observed in faecal bacterial populations (Swanson et al., 2002b; Terre et al., 2007). In our study, faecal concentration of Lactobacillus was lower $(p<0.05)$ in EG compared with $C G$ and no differences $(\mathrm{p}>0.05)$ in faecal concentrations of Bifidobacterium, $C$. perfringens and E. coli were found between $\mathrm{CG}$ and $\mathrm{EG}$ (Table 2). Grieshop et al. (2004) demonstrated that dietary supplementation with $1 \%$ MOS did not alter concentrations of faecal Lactobacillus and C. perfringens in dogs. However, Grieshop et al. (2004) reported that dogs supplemented with $1 \%$ MOS had a greater concentration of faecal Bifidobacterium compared with control dogs and MOS supplementation decreased concentration of faecal $E$. coli. Terre et al. (2007) observed that inclusion of $4 \mathrm{~g} / \mathrm{d}$ MOS into the milk replacer did not affect faecal concentrations of $C$. perfringens and E. coli in calves. In the study conducted by Swanson et al. (2002a), supplementation of $2 \mathrm{~g} / \mathrm{d}$ fructooligosaccharides plus $1 \mathrm{~g} / \mathrm{d}$ MOS did not decrease faecal concentrations of $C$. 
Table 2. Effect of MOS supplementation on faecal $\mathrm{pH}$, faecal bacterial populations, incidence of diarrhoea, treatment days for diarrhoea and the costs associated with diarrhoea treatments in calves

\begin{tabular}{|c|c|c|c|}
\hline \multirow{2}{*}{ Item } & \multicolumn{2}{|c|}{ Group } & \multirow{2}{*}{ p-value } \\
\hline & $\mathrm{CG}^{\mathrm{a}}(\mathrm{n}=10)$ & $E G^{b}(n=10)$ & \\
\hline \multicolumn{4}{|l|}{ Faecal pH } \\
\hline Day 5 & $5.68 \pm 0.14$ & $5.90 \pm 0.20$ & 0.392 \\
\hline Day 56 & $7.37 \pm 0.12$ & $7.46 \pm 0.08$ & 0.514 \\
\hline \multicolumn{4}{|l|}{ Faecal bacterial populations ${ }^{\mathrm{c}}$ (CFU $\log _{10} / \mathrm{g}$ fresh faeces) } \\
\hline Lactobacillus & $5.70 \pm 0.20$ & $5.09 \pm 0.17$ & 0.034 \\
\hline Bifidobacterium & $5.28 \pm 0.40$ & $5.59 \pm 0.14$ & 0.461 \\
\hline Clostridium perfringens & $4.15 \pm 0.41$ & $3.74 \pm 0.20$ & 0.336 \\
\hline Escherichia coli & $4.27 \pm 0.56$ & $4.70 \pm 0.36$ & 0.508 \\
\hline The incidence of diarrhoea (\%) & 40.00 & 50.00 & 1.000 \\
\hline Treatment days/calf treated for diarrhoea & $7.00 \pm 1.15$ & $5.40 \pm 0.98$ & 0.200 \\
\hline Cost of injectable antibiotic treatment ( $€ /$ calf treated for diarrhoea) & $2.77 \pm 0.69$ & $1.76 \pm 0.58$ & 0.190 \\
\hline Cost of total treatment $(€ / \text { calf treated for diarrhoea })^{\mathrm{d}}$ & $8.18 \pm 3.55$ & $6.08 \pm 2.60$ & 0.310 \\
\hline
\end{tabular}

MOS, mannanoligosaccharides; $\mathrm{CG}$, control group; EG, experimental group; $\mathrm{CFU}$, colony forming unit.

Values are presented as mean \pm standard error of the mean unless otherwise indicated.

${ }^{\mathrm{a}}$ Control group. ${ }^{\mathrm{b}}$ Group supplemented with MOS.

${ }^{\mathrm{c}}$ Bacterial populations in sterile faeces sampled from 8 of 10 and 9 of 10 calves in CG and EG, respectively, on day 56.

${ }^{\mathrm{d}}$ Cost of injectable and oral antibiotics, anti-inflammatory, immun stimulant, and electrolyte treatments.

perfringens and E. coli. Swanson et al. (2002a) observed that faecal Lactobacillus and Bifidobacterium concentrations were greater in dogs supplemented with fructooligosaccharides plus MOS compared to control dogs. Based on the current study and aforementioned studies (Finuance et al., 1999; Swanson et al., 2002a,b; Grieshop et al., 2004; Terre et al., 2007), it can be reported that effects of MOS supplementation on intestinal bacterial populations are inconsistent. Lactate is a major end-product of the lactate-producing species, Lactobacillus and Bifidobacterium, and is an antimicrobial substance. Lactateproducing bacteria can decrease colonic $\mathrm{pH}$ by producing lactate, which can suppress the growth of pathogen populations in the intestine (Swanson et al., 2002a,b). In our study, decreased Lactobacillus concentration in EG may have led to a reduction in lactate production. No reduce in concentrations of faecal C. perfringens and E. coli in EG may be partly associated with no decrease in faecal $\mathrm{pH}$ of the calves supplemented with MOS.

No difference $(\mathrm{p}>0.05)$ in body temperature was detected between groups throughout the study (Figure 2). Normal body temperature in calves ranges from $38.50^{\circ} \mathrm{C}$ to $39.50^{\circ} \mathrm{C}$ (Jackson and Cockcroft, 2002). Body temperature is a useful indicator of describing the health status of animals. Increased body temperature is an early sign of infection (Apanavicius et al., 2007). Calves with body temperature $>39.50^{\circ} \mathrm{C}$ were considered to be febrile. There were four calves having a higher body temperature than $39.50^{\circ} \mathrm{C}$ in both $\mathrm{CG}$ and $\mathrm{EG}$ during the study.

Diarrhoea developed in 4 of 10 and 5 of 10 calves in CG and EG, respectively, during the study. No difference $(p>0.05)$ in the incidence of diarrhoea was found between

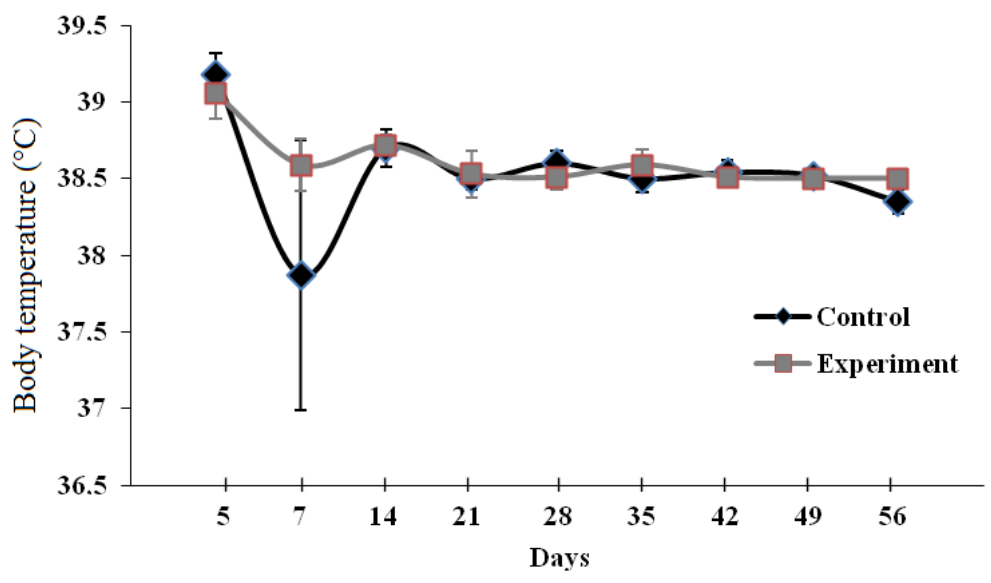

Figure 2. Mean ( \pm standard error of the mean) body temperatures of control $(\mathrm{CG}, \mathrm{n}=10)$ and experimental $(\mathrm{EG}, \mathrm{n}=10)$ calves. CG, control group; EG, experimental group. 
groups (Table 2). This result was supported by data from faecal score and faecal bacterial populations. A higher dose than $7 \mathrm{~g} / \mathrm{d}$ of MOS supplement may be necessary to decrease faecal concentrations of pathogenic bacteria and the occurrence of diarrhoea under the circumstances where the incidence of diarrhoea is high as observed in our study. Throughout the study, respiratory and other health problems were not observed in any group. In this study, there were no significant differences $(p>0.05)$ in the duration of treatments applied for diarrhoea (treatment days) and the costs associated with diarrhoea treatments between groups (Table 2). However, mean treatment days and costs of injectable antibiotic and total (injectable and oral antibiotics, anti-inflammatory, immun stimulant, and electrolyte products) treatments were numerically decreased in EG compared with CG. Magalhaes et al. (2008) also observed that treatment days with antibiotic and costs of total and antibiotic treatment were numerically decreased when calves were supplemented with yeast culture as a source of MOS. Uzmay et al. (2011) reported that while cost of antibiotics used for treatment of diarrhoea was higher for calves supplemented with $4 \mathrm{~g} / \mathrm{d}$ of MOS compared with control calves for day 5 to 25 , antibiotic treatment cost in day 26 to 46 was decreased by MOS supplementation in the whole milk.

In conclusion, during the preweaning period, MOS supplementation in the whole milk did not significantly affect growth performance parameters in calves. Supplementation of MOS did not positively alter bacterial populations in faeces and did not significantly affect the incidence of diarrhoea, treatment days for diarrhoea and the costs associated with diarrhoea treatments. Higher doses than $7 \mathrm{~g} / \mathrm{d}$ of MOS supplement may be necessary to decrease faecal concentrations of pathogenic bacteria and the occurrence of diarrhoea under the conditions of the present study where the incidence of diarrhoea is high. The observed decreases in treatment days and the cost of diarrhoea treatments for the calves supplemented with MOS were accompanied by increases in final body weight (3.70\%), ADG (6.66\%) and ADFI (10.97\%), collectively, which may indicate potential benefit of MOS in treatment of diarrhoea in calves.

\section{CONFLICT OF INTEREST}

We certify that there is no conflict of interest with any financial organization regarding the material discussed in the manuscript.

\section{ACKNOWLEDGMENTS}

The authors would like to thank workers of Uludag University Applied Research Center for Veterinary Faculty
Unit for help during the study.

\section{REFERENCES}

Ao, Z. and M. Choct. 2013. Oligosaccharides affect performance and gut development of broiler chickens. Asian Australas. J. Anim. Sci. 26:116-121.

Apanavicius, C. J., K. L. Powell, B. M. Vester, L. K. KarrLilienthal, L. L. Pope, N. D. Fastinger, M. A. Wallig, K. A. Tappenden, and K. S. Swanson. 2007. Fructan supplementation and infection affect food intake, fever, and epithelial sloughing from Salmonella challenge in weanling puppies. J. Nutr. 137:1923-1930.

da Silva J. T., C. M. Bittar, and L. S. Ferreira. 2012. Evaluation of mannan-oligosaccharides offered in milk replacers or calf starters and their effect on performance and rumen development of dairy calves. R. Bras. Zootec. 41:746-752.

Davis, C. L. and J. K. Drackley. 1998. The Development, Nutrition and Management of the Young Calf. Iowa State University Press, Ames, IA, USA.

Demirel, G., N. Turan, A. Tanor, N. Kocabagli, M. Alp, M. Hasoksuz, and H. Yilmaz. 2007. Effects of dietary mannanoligosaccharide on performance, some blood parameters, IgG levels and antibody response of lambs to parenterally administered E. coli O157:H7. Arch. Anim. Nutr. 61:126-134.

Finuance, M. C., K. A. Dawson, P. Spring, and K. E. Newman. 1999. The effect of mannan oligosaccharide on the composition of the microflora in turkey poults. Poult. Sci. 78(Suppl. 1):77(Abstr.).

Ghosh, S. and R. K. Mehla. 2012. Influence of dietary supplementation of prebiotics (mannanoligosaccharide) on the performance of crossbred calves. Trop. Anim. Health Pro. 44:617-622.

Giannella, R. A. 1983. Escherichia coli heat-stable enterotoxin: Biochemical and physiological effects in the intestine. Prog. Food. Nutr. Sci. 7:157-165.

Gibson, G. R. and M. B. Roberfroid. 1995. Dietary modulation of the human colonic microbiota: introducing the concept of prebiotics. J. Nutr. 125:1401-1412.

Grand, E., F. Respondek, C. Martineau, J. Detilleux, and G. Bertrand. 2013. Effects of short-chain fructooligosaccharides on growth performance of preruminant veal calves. J. Dairy Sci. 96:1094-1101.

Grieshop, C., E. Flickinger, K. Bruce, A. R. Patil, G. L. CzarneckiMaulden, and G. C. Fahey. 2004. Gastrointestinal and immunological responses of senior dogs to chicory and mannan-oligosaccharides. Arch. Anim. Nutr. 58:483-493.

Heinrichs, A. J., C. M. Jones, and B. S. Heinrichs. 2003. Effects of mannan oligosaccharide or antibiotics in neonatal diets on health and growth of dairy calves. J. Dairy Sci. 86:4064-4069.

Heinrichs, A. J., B. S. Heinrichs, and C. M. Jones. 2013. Fecal and saliva IgA secretion when feeding a concentrated mannan oligosaccharide to neonatal dairy calves. Prof. Anim. Sci. 29:457-462.

Hill, T. M, H. G. Bateman, J. M. Aldrich, and R. L. Schlotterbeck. 2008. Oligosaccharides for dairy calves. Prof. Anim. Sci. 24:460-464. 
Hill, S. R., B. A. Hopkins, S. Davidson, S. M. Bolt, D. E. Diaz, C. Brownie, T. Brown, G. B. Huntington, and L. W. Whitlow. 2009. The addition of cottonseed hulls to the starter and supplementation of live yeast or mannanoligosaccharide in the milk for young calves. J. Dairy Sci. 92:790-798.

Jackson, P. G. and P. D. Cockcroft. 2002. Normal physiological values. In: Clinical Examination of Farm Animals (Eds. P. G. Jackson and P. D. Cockcroft). Wiley-Blackwell, Oxford, UK. p. 301.

Jacques, K. A. and K. E. Newman. 1994. Effect of oligosaccharide supplements to milk replacer on calf performance and health preweaning. J. Anim. Sci. 72(Suppl. 1):1139(Abstr.).

Kanakupt, K., B. M. Vester Boler, B. R. Dunsford, and G. C. Fahey. 2011. Effects of short-chain fructooligosaccharides and galactooligosaccharides, individually and in combination, on nutrient digestibility, fecal fermentative metabolite concentrations, and large bowel microbial ecology of healthy adults cats. J. Anim. Sci. 89:1376-1384.

Lebel, A., J. J. Matte, and F. Guay. 2014. Effect of mineral source and mannan oligosaccharide supplements on zinc and copper digestibility in growing pigs. Arch. Anim. Nutr. 68:370-384.

Magalhães, V. J, F. Susca, F. S. Lima, A. F. Branco, I. Yoon, and J. E. P. Santos. 2008. Effect of feeding yeast culture on performance, health, and immunocompetence of dairy calves. J. Dairy Sci. 91:1497-1509.

Morrison, S. J., S. Dawson, and A. F. Carson. 2010. The effects of mannan oligosaccharide and Streptococcus faecium addition to milk replacer on calf health and performance. Livest. Sci. 131:292-296.

Newman, K. 1994. Mannan-oligosaccharides: Natural polymers with significant impact on the gastrointestinal microflora and the immune system. In: Proceedings of Alletch's 10th Annual Symposium, Nottingham University Press, Nottingham, United Kingdom. pp. 167-174.
Shane, S. M. 2001. Mannan oligosaccharides in poultry nutrition, mechanisms and benefits. In: Proceedings of Alletch's 17th Annual Symposium, Nottingham University Press, Nottingham, United Kingdom, pp. 65-77.

Spring, P., C. Wenk, K. A. Dawson, and K. E. Newman. 2000. The effects of dietary mannanoligosaccharides on cecal parameters and the concentrations of enteric bacteria in the ceca of Salmonella-challenged broiler chicks. Poult. Sci. 79:205-211.

SPSS. 2004. Statistical Package for the Social Sciences. Base system user's guide, version 5.0. SPSS Inc., Chicago, IL, USA.

Swanson, K. S., C. M. Grieshop, E. A. Flickinger, H. P. Healy, K. A. Dawson, N. R. Merchen, and G. C. Fahey. 2002a. Effects of supplemental fructooligosaccharides plus mannanoligosaccharides on immune function and ileal and fecal microbial populations in adult dogs. Arch. Anim. Nutr. 56:309-318.

Swanson, K. S., C. M. Grieshop, E. A. Flickinger, L. L. Bauer, H. P. Healy, K. A. Dawson, N. R. Merchen, and G. C. Fahey. 2002b. Supplemental fructooligosaccharides and mannanoligosaccharides influence immune function, ileal and total tract nutrient digestibilities, microbial populations and concentrations of protein catabolites in the large bowel of dogs. J. Nutr. 132:980-989.

Terre, M., M. A. Calvo, C. Adelantado, A. Kocher, and A. Bacha. 2007. Effects of mannan oligosaccharides on performance and microorganism fecal counts of calves following an enhancedgrowth feeding program. Anim. Feed Sci. Tech. 137:115-125.

Uzmay, C., A. Kılıc, I. Kaya, H. Ozkul, S. S. Onenc, and M. Polat. 2011. Effect of mannan oligosaccharide addition to whole milk on growth and health of Holstein calves. Arch. Tierzucht. 54:127-136.

White, L. A., M. C. Newman, G. L. Cromwell, and M. D. Lindemann. 2002. Brewers dried yeast as a source of mannan oligosaccharides for weanling pigs. J. Anim. Sci. 80:2619-28.

Zhao, P. Y., J. H. Jung, and I. H. Kim. 2012. Effect of mannan oligosaccharides and fructan on growth performance, nutrient digestibility, blood profile, and diarrhea score in weanling pigs. J. Anim. Sci. 90:833-9. 